\title{
NI HABLAR, NI PENSAR, NI SOÑAR ANÁLISIS HISTÓRICO DE SU TRANSFORMACIÓN EN UNIDADES FRASEOLÓGICAS*
}

Entre las construcciones fijas de las que dispone el español actual para manifestar de forma expresiva una negación o para rechazar una propuesta se encuentran ni hablar, ni pensar, ni soñar. En las páginas que siguen pretendo ofrecer un examen diacrónico, en concreto por medio de los datos que ofrece la Real Academia Española ${ }^{1}$ de estas tres secuencias y sus variantes; un análisis sintáctico-semántico que permita observar la motivación que ha dado origen a su valor idiomático ${ }^{2}$ y, además, descubrir el momento en que se manifiestan con todos los requisi-

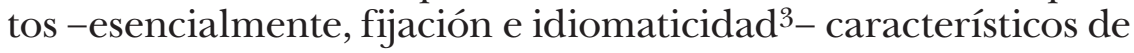

* Este trabajo se ha realizado en el marco del Proyecto de investigación Teoría y análisis de los discursos. Estrategias persuasivas y de interpretación, perteneciente al Plan de Investigación de la Universidad de Navarra.

${ }^{1}$ Real Academia Española, Corpus diacrónico del español y Corpus de referencia del español actual, ambos, bancos de datos en línea que se pueden consultar en http://www.rae.es. En adelante, cito por CORDE y CREA, respectivamente. Como se verá, he tenido en cuenta manifestaciones de todas las procedencias geográficas para comprobar si se advierten diferencias diatópicas en el uso y desarrollo de las secuencias que analizo.

2 La incorporación de la perspectiva diacrónica en el estudio de las unidades fraseológicas es reciente. Véase M.T. Echenique, "Pautas para el estudio histórico de las unidades fraseológicas", Estudios ofrecidos al profesor J.J. de Bustos Tovar, eds. J.L. Girón Alconchel, F.J. Herrero, S. Iglesias y A. Narbona, Universidad Complutense, Madrid, 2003, pp. 545-560, que habla sobre la necesidad de la dimensión diacrónica en la investigación sobre fraseología; la autora presenta, además, una guía metodológica.

3 Son los rasgos que L. Ruiz Gurillo considera matrices para las unidades fraseológicas (Aspectos de fraseología teórica española, Universidad, Valencia, 1997, p. 104). Acerca de la idiomaticidad, en un trabajo reciente todavía inédito y que se integra en el mismo proyecto de investigación que este artículo, I. Olzza Moreno, Fraseología, idiomaticidad y metáfora. Aproximación a los somatismos metalingüisticos del español actual, tesis de licenciatura, 
una unidad fraseológica. Una vez alcanzada esta condición es mi intención mostrar que han adquirido la capacidad de negar expresivamente constituyendo por sí solas un enunciado (esto es, como enunciados fraseológicos) o bien como elementos oracionales, rasgo éste que se tiene como propio de las locuciones ${ }^{4}$.

\section{NI HABLAR. UNA FÓRMULA PRAGMÁTICA DEL SIGLO XX}

$\mathrm{Si}$, como acabo de exponer, ni hablar es una fórmula capaz de manifestar una negación o una negativa, es posible situarla en un paradigma de secuencias -también unidades fraseológicasque comparten con ella esa capacidad. Me permito citar, además de las que anuncia el título de este trabajo, las secuencias en absoluto o de ninguna manera ${ }^{5}$. Su pertenencia a un mismo para-

Universidad, Navarra, 2006, presenta una revisión rigurosa de este concepto, desde C. Bally hasta los trabajos más recientes, desde la idea tradicional que la define como propiedad semántica, por la cual el sentido global de una expresión no es deducible a partir de los significados de sus elementos, hasta las reinterpretaciones radicales, pasando por matizaciones como las de G. Wotjak o L. Ruiz Gurillo. Sobre la fijación (repetición sin alteración del orden, de las categorías gramaticales, del inventario de componentes), véase A. Zuluaga, Introducción al estudio de las expresiones fijas, Max Niemeyer, Tübingen, 1980, pp. 95 ss. Consúltese, además, el reciente e imprescindible trabajo de E.T. Montoro DEL ArCo, Teoría fraseológica de las locuciones particulares. Las locuciones prepositivas, conjuntivas y marcadoras en español, $\mathrm{P}$. Lang, Frankfurt/M., 2006, § 2, para una explicación pormenorizada de los rasgos básicos de las unidades fraseológicas.

4 Véase, sobre el concepto, características y clasificación de las locuciones, J. CASARES, Introducción a la lexicografía moderna, CSIC, Madrid, 1992, pp. 167-184. Casares considera que el hecho de que algunas locuciones puedan constituir oraciones no anula su condición de locuciones (pp. 181182). Para una revisión rigurosa de las definiciones y clasificaciones de las locuciones, desde Casares hasta la actualidad, consúltese E.T. Montoro DEL Arco, op. cit., pp. 98-105. M. García-PAge ("La locución oracional en español”, en Fraseología e ironía. Descripción y contraste, ed. J. García Medall, Editorial Axac, Lugo, 2006, pp. 71-83), revisa también las clasificaciones que se han propuesto de las locuciones y ofrece una, según un criterio estructural, que le permite distinguir entre locuciones verbales, cuasioracionales y oracionales. Sobre las características y clasificación de las locuciones -incluida una revisión crítica y actualizada de propuestas-, véase, también, el más reciente trabajo de M. GARCíA-PAGE, Introducción a la fraseología española. Estudio de las locuciones, Anthropos, Barcelona, 2008, §§ 2 y 3.

5 G. Corpas incorpora ni hablar entre los enunciados fraseológicos que denomina fórmulas expresivas, en concreto entre las de recusación (Manual de fraseología española, Gredos, Madrid, 1996, pp. 192-196). M. Aznárez sitúa 
digma no impide observar una diferencia que atañe al grado de formalidad: ni hablar está marcada con el rasgo de coloquialidad, quizá porque negar al interlocutor la posibilidad de hablar, o negarse a hablar con él de algo (tal vez, por tanto, nunca llega a hacerse opaco el significado del infinitivo; cf. infra, sobre la idiomaticidad), obliga a presuponer un alto grado de confian$\mathrm{za}^{6}$. En cualquier caso, esta disparidad en cuanto al registro no anula -tal vez sólo matiza- sus posibilidades de aparecer en los mismos contextos.

Sí son, no obstante, muy diversas las consideraciones que obtienen en las obras lexicográficas actuales. Ni hablar no recibe habitualmente el apellido de "locución", que sí merecen las otras ${ }^{7}$, tal vez porque se entiende prioritario su empleo como fórmula pragmáticamente especializada, y por tanto

ni hablar entre las fórmulas de negación o rechazo (La fraseología metalingüistica con verbos de lengua en español actual, P. Lang, Frankfurt/M., 2006, pp. 395397). M. GARCíA-PAGE considera ni hablar entre las locuciones interjectivas capaces de funcionar como enunciados independientes en una réplica (op. cit., p. 340). No se agota aquí, desde luego, la nómina de secuencias con estos valores. G. Corpas incluye, además, qué va; nada de eso; naranjas de la China; vamos, anda, etc. (op. cit., pp. 195-198); J. CASARES menciona no en mis días y ni por esas (op. cit., p. 180). Más fórmulas en J. Casares, Diccionario ideológico de la lengua española, Editorial Gustavo Gili, Barcelona, 1999, p. 310: ni por asomo, no ha lugar, no hay tu tía, etc. (este autor no recoge ni hablar). En C. PÉrEz-SAlazar, "Unidades fraseológicas y diacronía. Sobre las fórmulas de ninguna manera y en absoluto", EHF, 29 (2007), 253-281, presento un análisis diacrónico de las fórmulas de ninguna manera y en absoluto, de ahí mi interés en ofrecer una comparación entre éstas y ni hablar. Más fórmulas negativas en J.J. AsEnsio, "Fórmulas de negación sin partículas negativas", en Estudios de fraseología y fraseografía del español actual, ed. G. Wotjak, VervuertIberoamericana, Frankfurt/M.-Madrid, 1998, pp. 203-224.

6 M. Moliner anota "informal" en su Diccionario de uso del español, $2^{\text {a }}$ ed., Gredos, Madrid, 1998, s.v. "hablar"; M. Seco, O. Andrés y G. Ramos la consideran coloquial (Diccionario del español actual, Aguilar, Madrid, 1999, s.v. "hablar"); en cambio, M. Seco, O. Andrés y G. Ramos, en Diccionario fraseológico documentado del español actual. Locuciones y modismos españoles, Aguilar, Madrid, 2004, s.v. "hablar", amplían su ámbito y anotan "formal o coloquial". Véase, infra, y testimonios 28 ss., sobre su documentación en situaciones de informalidad.

7 Las secuencias de ninguna manera y en absoluto son locuciones, según la Real Academia Española (Diccionario de la lengua española, 22a ed., Espasa, Madrid, 2001), y M. Moliner (op. cit., s.v. "manera” y "absoluto"); en cambio, de ninguna manera es expresión para M. MolineR (s.v. "manera"), que no califica en absoluto. Ni hablar es expresión en el DRAE de 2001 y en M. Moliner (op. cit., s.v. "hablar"), y fórmula según M. Seco, O. Andrés y G. Ramos (Diccionario del español actual..., s.v. "hablar"). Cf., infra, sobre las 
como enunciado independiente, o porque conserva plenamente, junto a su valor adquirido, la capacidad de actuar como secuencia no formularia integrada en una oración (no quiere ni comer ni hablar), o porque, aun en uso formulario, admite la presencia de un incremento del verbo en forma de complemento regido (ni hablar de eso, o de eso ni hablar, representa la forma más frecuente de este desarrollo argumental) ${ }^{8}$.

$\mathrm{Si}$ al comenzar este apartado he adscrito la fórmula ni hablar al siglo xx, no cabe afirmar lo mismo acerca de la presencia de esta secuencia integrada en unidades superiores en las que participa con valor semántico pleno, al igual que sucede con otras que comparten estructura y componentes y están semánticamente próximas: ni decir, ni comentar, ni contestar, ni responder, ni explicar, ni mencionar, etc. La secuencia ni+ infinitivo es, pues, históricamente productiva en nuestro idioma, pero no siempre ha dado lugar a unidades fraseológicas.

Ocho siglos después de sus primeras apariciones, esto es, entrado el siglo xx, esta secuencia aparece por vez primera, como se verá, convertida en unidad fraseológica. Curiosamente, esa transformación es exclusiva, de entre las arriba nombradas, para ni hablar; es decir, no sucede -pero podría haber sucedidocon construcciones estructuralmente iguales en las que interviene otro verbo de lengua. Así pues, los hablantes han seleccionado sólo una, precisamente la que incorpora la unidad verbal de significado menos preciso. En cambio, encontramos una transformación semejante en las mismas secuencias con verbos ajenos a este campo semántico: ni pensar(lo), ni soñar(lo), que cabría

consideraciones que reciben ni soñar(lo) y ni pensar(lo). Sí incluye ni hablar entre las locuciones, M. García-PAGE (op. cit., p. 340).

8 Sin embargo, según afirma L. Ruiz Gurillo, las locuciones, "aun comportándose en bloque como una unidad, actúan en el discurso y se acomodan a él; alteran el orden de sus elementos, permiten pequeñas modificaciones o, si son verbales, varían el tiempo, el aspecto o el modo, sin perder por ello su idiosincrasia" (Las locuciones en español actual, Arco/ Libros, Madrid, 2001, p. 27). Añádase a esto que la fórmula equivalente $n i$ pensarlo es considerada locución adverbial por M. SEco, O. Andrés y G. Ramos (Diccionario fraseológico documentado...), y que ni soñarlo recibe este apelativo en el DRAE de 2001 (s.v. "soñar"), como se verá más adelante. M. GARCía-PAGE considera que la locución "puede tener, en calidad de unidad fraseológica, no sólo estructura de elemento oracional (generalmente, un sintagma), sino también estructura de oración completa" (art. cit., p. 75). Véase G. Corpas (op. cit., pp. 50-52), para una propuesta de clasificación de las unidades fraseológicas en tres tipos: combinaciones, locuciones y enunciados fraseológicos. 
considerar unidades fraseológicas actualmente sinónimas de la que aquí se describe ${ }^{9}$. De hecho, ese valor coincidente parece originarse históricamente en virtud de un sema común: todas ellas han compartido, en un momento determinado, la interpretación de las acciones designadas por sus infinitivos como actividades básicas del ser humano, respectivamente, las capacidades de expresarse verbalmente ${ }^{10}$, de razonar y de representar algo imaginativamente de forma inconsciente.

En cualquier caso, el cambio (de secuencia integrada en un enunciado a unidad fraseológica) no es repentino, o, lo que es lo mismo, el uso como locución que manifiesta una negación rotunda o como fórmula pragmática especializada en la recusación no surge de pronto y sin tránsito, aunque la aparición de testimonios de ese valor adquirido así lo sugiera; al contrario, es posible descubrir cómo y a partir de qué contextos puede haber desarrollado la secuencia la condición de unidad fraseológica, en la que el sentido idiomático atenúa su significado original ${ }^{11}$.

En sus primeras apariciones, ni hablar (o ni fablar) se encuentra siempre en enunciados en los que se coordinan al menos dos infinitivos, si no precedidos de negación, sí en un entorno negativo $^{12}$. En cuanto al significado del infinitivo, junto a testimonios en los que hablar transmite su valor conceptual pleno (testimonios 5 y 7 , por ejemplo), me permito destacar -porque a partir de ellos puede originarse el valor idiomático- los contextos en que ni hablar se coordina a otro u otros infinitivos para transmitir, desarrollado en varios miembros, y por tanto más explícita y más expresivamente que con una única frase de significado más amplio (hacer nada, por ejemplo), todo lo que nie-

9 Se trata de una sinonimia externa, que es la que se produce entre expresiones diferentes pero de valor idéntico o semejante; más precisamente, ni hablar, ni soñary ni pensar son variantes sinonímicas, porque presentan la misma estructura gramatical, pero varían los signos léxicos. Véase M. GARCíA-PAGE, "Expresión fija y sinonimia”, en Estudios de fraseología..., pp. 83-91, sobre dos tipos de sinonimia en las unidades fraseológicas.

10 Entre los verbos de lengua, precisamente hablarse puede tomar como archilexema de la interacción lingüística. Así, en M. AznÁrez, op. cit., p. 28, n. 34.

11 Como afirma M.T. EcheniQue: "la búsqueda del sentido originario y su relación con el sentido idiomático es una búsqueda de carácter histórico" (art. cit., p. 553).

12 A veces, en lugar de una negación explícita, existe un contexto que activa esa negatividad. Nótese, por ejemplo, que en el testimonio del Corbacho la exclamación ejerce de activador negativo. Sobre las locuciones con estructura negativa, véase M. GARcía-PAGE, op. cit., pp. 334-336. 
ga el verbo que los rige (obsérvense los testimonios 1, 6, 8 y 11). En estos contextos se puede afirmar que el contenido de hablar empieza a desdibujarse.

La Edad Media ofrece pocas apariciones de ni hablar (además, de las 25 halladas en el CORDE, 20 pertenecen al siglo $\mathrm{Xv}^{13}$ ). Valga señalar que no existe para esta secuencia un tipo textual característico ${ }^{14}$ :

(1) Que no les deuen dar paz a la missa, ni fablar les, ni deuen orar con ellos en ningún logar (1256-1263, Alfonso X, Primera Partida).

(2) Pocos son los hombres que se miembran de lo passado porque no quieren pensar ni hablar de lo que recibieron (13001305, anónimo, Libro del caballero Cifar).

(3) Diziendo loco atreuido do te vino osar de escriuir ni hablar de aquellas que merescen del mundo la victoria (1438, Alfonso Martínez de Toledo, Arcipreste de Talavera o Corbacho).

(4) No me es mandado replicar ni hablar más en esta materia (1480-1484, Hernando del Pulgar, Crónica de los Reyes Católicos).

(5) Porque muy pocos dellos saben entender ni hablarsino arábigo (1500, anónimo, Los Reyes Católicos a maestre Martín García...).

El español clásico deja ver más testimonios, pero no varían las circunstancias sintáctico-semánticas descritas, es decir, la secuencia ni hablar forma parte de una estructura coordinativa, y el infinitivo hace referencia al hecho de comunicarse:

13 Tras el testimonio, que reproduzco tal como aparece en la base de datos académica, indico año, autor y obra -o, en su caso, documento y obra; artículo y obra; artículo o sección y publicación periódica; espacio y programa. Presento los testimonios organizados, en cada apartado (ni hablar en estructuras coordinadas; ni hablar dependiente de un verbo; ni hablar como secuencia independiente), en orden cronológico. Indico el país del que proceden los testimonios cuando interese introducir algún comentario acerca del factor diatópico.

14 En cambio, la secuencia de ninguna manera y sus variantes aparecen asociadas a un tipo de texto, puesto que se hallan esencialmente, en sus primeras manifestaciones, en textos de carácter legal (véase C. Pérez-SAlazar, art. cit., pp. 257-258) 
(6) No le es lícito andar fuera, ni salir de casa, ni hablar con los estraños (1529-1531, fray Antonio de Guevara, Reloj de príncipes).

(7) Mas hanlas tenido dos meses sin oír misa ni hablar con los confesores (1577, "Carta al P. Gaspar de Salazar en Granada”, en Epistolario).

(8) Puede escandalizar al seglar imprudente, que piensa que, porque uno se hizo religioso reformado, ya no ha de comer, beber, dormir ni hablar (1607, san Juan Bautista de la Concepción [Juan García Gómez], De los oficios más comunes).

(9) Y advierta el que picare que entre tanto que picare no ha de toser, ni hablar, ni ha de hazer otra cosa ninguna (1611, Francisco Martínez Motiño, Arte de cozina, pastelería, vizcochería y conseruería).

(10) Nunca más le han visto reír ni hablar razón concertada (1615, Miguel de Cervantes, Segunda parte del ingenioso caballero don Quijote de la Mancha).

Me permito dedicar un comentario aparte a los casos en que ni hablar aparece acotado con el complemento palabra. La secuencia negación + hablar palabra (que también puede integrarse en estructuras coordinativas) ofrece testimonios desde la Edad Media -siempre según el CORDE-, y ha alcanzado cierto grado de idiomaticidad, aunque desligada de la que aquí se analiza $^{15}$; se refiere expresivamente al silencio del hablante ${ }^{16}$ y forma parte de un nutrido grupo de locuciones que, en nuestro idioma, manifiestan el mismo contenido ${ }^{17}$ :

15 No es mi intención, por este motivo, perseguir en estas páginas su desarrollo histórico, pero sí quiero mencionar su rápida difusión: en el siglo XVI, el CORDE ofrece ya más de doscientos testimonios de la fórmula negación + hablar palabra, considerando sólo las manifestaciones con el verbo en infinitivo.

16 Como afirma E. Coseriu: "como suspensión intencional del hablar, el callar puede incluso convertirse en medio expresivo" (El hombre y su lenguaje. Estudios de teoría y metodología lingüistica, Gredos, Madrid, 1985, p. 14). En estas secuencias, el énfasis reside en el hecho de acotar el significado de hablar (no hablar, en este caso), con un término que representa un desarrollo muy escaso, la palabra, como sucede en no decir ni pí, ni anjo o ni mu. Véase, respecto de estas secuencias, M. AznÁrez, op. cit., pp. 126-127. El mismo procedimiento de negación expresiva se produce en importar o valer un comino, un pimiento, etc.

$17 \mathrm{M}$. AznÁrez incluye estas secuencias entre las locuciones nominales en colocaciones complejas (op. cit., p. 67); en pp. 123-125 menciona y comen- 
An estado sin le fablar palabra (1378-1406, Pero López de Ayala, Rimado de Palacio).

Nin más pudo fablar palabra (1400, Biblia romanceada).

No querían responder ni hablar palabra hasta que el soldán hablasse (1555, Diego Ortúñez de Calahorra, Espejo de príncipes y caballeros).

Y se quedó también por gran pieza sin moverse ni hablar palabra (1587, Fernando de Mena, traducción de la Historia etiópica de los amores de Teágenes y Cariclea, de Heliodoro).

Respecto de la secuencia que aquí se analiza, el siglo XVIII representa un importante descenso en cuanto a frecuencia de aparición de ni hablar (que ya se inicia en el XVII) ${ }^{18}$. Se mantienen, en cualquier caso, las circunstancias expuestas hasta aquí: ni hablar forma parte de una coordinación y aporta significado pleno:

(11) De tal suerte que no osaba levantar los ojos, ni hablar (1709, Gertrudis de San Ildefonso, La perla mistica escondida en la concha de la humildad).

(12) Pero estos estaban tan desanimados y desatendidos, que no se atrevían á sacar la cara, ni hablar en público (1770, fray Agustín María de Castro y Amuedo, "Relación de la toma de Manila por la escuadra inglesa", en Documentos indispensables para la verdadera...).

Del siglo XIX no interesa tanto la presencia creciente de $n i$ hablar (que ofrece ya 42 testimonios) como el hecho de que por primera vez abandona el marco de la coordinación, esto es, aparece como complemento verbal único -siempre en contextos negativos-junto a verbos, según se aprecia en el CORDE, como poder o saber. En este entorno, la noción de 'hablar' se puede entender como representación de actividad mínima, de manera que se desdibuja o pasa a un segundo plano (aunque no deje de estar presente) el significado literal de 'no ser capaz o no tener

ta no decir palabra, no hablar palabra, de las que existen variantes: no decir ni (media) (una) palabra, no hablar ni (media) (una) palabra, no pronunciar ni (media) (una) palabra, sin decir/hablar palabra, etc.

18 Los datos numéricos hallados en el CORDE así lo muestran: 110 casos en el siglo XVi; 79 en el xvir; 13 en el xviII. 
la oportunidad de comunicarse verbalmente', para imponerse el más expresivo de 'no ser capaz o no tener la oportunidad de hacer ni lo más básico', esto es, 'no ser capaz o no tener la oportunidad de hacer nada'.

Quiero destacar que los diez testimonios de este siglo en que se cumplen las características ahora descritas proceden de diversos países hispanohablantes -así pues, el factor diatópico no revela diferencias en cuanto al momento de aparición de $n i$ hablar como complemento único, siempre a falta de una comprobación más rigurosa en otras fuentes. Ahora bien, si la procedencia geográfica de los testimonios es variada, hay factores que comparten y que se deben destacar: todos se encuentran en contextos expresivos, bien en reproducciones de diálogos (como 14 y 15) o bien en reflexiones monológicas (como 13, de contenido irónico, o 16 y 17, más emotivas). La mayor parte pertenece a textos literarios:

(13) ¿La niña lee mal, escribe peor, no conoce un número...? No importa, es mujer, no ha de ser sacerdotisa, ni jurista, ni médica, etc., etc., y así nada se pierde con que no sepa ni hablar (1818, José Joaquín Fernández de Lizardi, La Quijotita y su prima, México).

(14) Yo. Todos mis amigos han sido víctimas... No puedo ni hablar con las personas sin que caigan en desgracia (18511855, José Mármol, Amalia, Argentina).

(15) Ese hombre no sabe ni hablar-dijo ásperamente Constancia (1852, Fernán Caballero, Clemencia, España).

(16) ¡Si él supiera... si él supiera que no podía ni hablar...! (18841885, Clarín, La Regenta, España).

(17) ¡Pues ai nos traían al muchacho moribundo! Me levanté, me tiré la ropita como pude, y fui a ver: no podía ni hablar, ardido de fiebre, tosiendo lo más feo y quejándose que aquello partía el alma (1896, Tomás Carrasquilla, Frutos de mi tierra, Colombia).

Con todo, sigue siendo constante en esta centuria, y todavía mayoritaria, la presencia de ni hablar como miembro de una coordinación a la que aporta un significado pleno, que también sucede en testimonios de variados orígenes: 
(18) Las personas introducidas, ni deben estar ociosas, ni hablar más de lo que conviene (1811-1813, fray Francisco Alvarado, Cartas críticas del filósofo rancio, II, España).

(19) En América no se podía ser honrado, ni pensar ni hablar (1889, José Martí, La Edad de Oro, Cuba).

(20) Deliraba Julio, tenía gestos vagos, con los brazos, con la cabeza; sin ocurrirle amenazar, ni hablar alto, ni publicar sus derechos (1896, Federico Gamboa, Suprema ley, México).

Y esta posibilidad -que no menciono más porque ha quedado desvinculada de la fórmula que aquí interesa- continúa, como es sabido, hasta nuestros días ${ }^{19}$ :

(21) Con la cabeza baja y los brazos cruzados, sin reír ni hablar (1916, Vicente Blasco Ibáñez, traducción de Las mil y una noches).

(22) No puedo hacer otra cosa que cerrar los ojos y estarme quedo como quien deja pasar el escorpión, y no pensar $n i$ hablar cuando se trata de candidaturas (1923, Marco Fidel Suárez, Sueños de Luciano Pulgar).

(23) ¿No has observado que en el bosque nadie puede mentir, ni llorar, ni hablaralto para no despertar a los muertos? (19401974, Luis Rosales, El contenido del corazón).

(24) Y no tomar chocolate ni hablar por teléfono antes de irse a la piltra (1994, "Para dormir eludir el teléfono. [De los periódicos]”, en La Vanguardia).

Durante el siglo xx se manifiesta de forma creciente la aparición de ni hablar descrita para el xıx, esto es, fuera de una estructura coordinada y asociada a verbos como saber o poder. La presencia de ni hablar en estos contextos se mantiene también hasta hoy:

(25) ¿Ve usted? No puedo ni hablar; estoy loco (1928, Plauderer, en Lecturas).

19 Como propone L. Ruiz Gurillo ni hablar en estos contextos sería un homófono literal de la unidad fraseológica que aquí se persigue, una expresión "formalmente idéntica con un significado no figurado" (op. cit., p. 100). 
(26) Eso es que parece muerto, que es descoli... ya no sé $n i$ hablar..., des- colo-rido, vaya... (1933-1946, Miguel Ángel Asturias, El señor presidente).

(27) -Ya en este país ni hablar se puede. -Lo que no se puede es gritar (1964-1967, Guillermo Cabrera Infante, Tres tristes tigres).

(28) Aquí no se puede ni hablar que ya te vacunan (1997, "Las estaciones de servicio entran en la mira gastronómica", en La Nueva Provincia).

A partir de enunciados como estos, una vez que ha empezado a desdibujarse, como he señalado, el significado literal del infinitivo para dejar paso al sentido de actividad mínima posible, nada impide pensar en una etapa siguiente (que no tiene por qué suceder siempre, obviamente, como prueba el hecho de que este tipo de enunciados -no puedo ni hablar, no sabe ni hablar- tiene continuidad) en la que no se presenta el verbo del que depende la secuencia ni hablar (esto es, querer, saber, poder, etc.), de manera que ésta adquiere autonomía, y con ella la capacidad de expresar una negación de forma enfática (es decir, se incorpora al paradigma de expresiones como de ninguna manera, de ningún modo, en absoluto, etc.). Un paso posterior, aunque no necesario, la sitúa en contextos en los que ya ni siquiera interesa la noción de 'hablar' (esto se aprecia especialmente cuando el infinitivo hablar no va acompañado del incremento preposicional que rige). Valga señalar, además, que la fórmula enfática ni hablar puede aparecer tanto en pasajes monológicos como en secuencias dialogadas ${ }^{20}$.

En definitiva, la transformación histórica de ni hablar se podría ejemplificar así:

20 Según M. Aznárez estas fórmulas rutinarias están motivadas “por una intervención anterior del interlocutor, es decir, la mayor parte de ellas aparece en turnos reactivos o en réplicas" (op. cit., pp. 76-77). Señala, no obstante, que también se emplean como recurso "en discursos no dialógicos en los que el hablante rechaza o niega algo que, si bien no es pronunciado efectivamente por el interlocutor, se presenta en cualquier caso como una información, idea u opinión ajena” (p. 397). Tal vez quepa añadir que esa idea u opinión no tiene que ser necesariamente ajena: es posible que el hablante rechace o niegue algo dicho o pensado por sí mismo, si bien en el caso de hablar cabe entender que subyace siempre la idea de una interlocución, mientras que en el caso de pensar o soñar esto no sucede. 

a. - ¿Quieres venir a cenar?
-Hoy no puedo ni moverme, ni oír ni hablar.
b. -¿Quieres venir a cenar?
-Hoy no puedo ni hablar.
c. - ¿Quieres venir a cenar?
-Hoy, ni hablar.

Soy consciente de que mi interpretación de los datos no ha de ser necesariamente compartida, pero creo posible afirmar que el orden cronológico que manifiestan los testimonios del CORDE contribuye a sustentarla: históricamente, sucede antes la aparición de ni hablar como miembro de una coordinación de infinitivos a la que aporta significado pleno; le sigue su empleo fuera de una coordinación, dependiente de los verbos arriba citados, como representación de una actividad mínima; y, por último, aparece de forma autónoma para manifestar una negación expresivamente.

Los testimonios que siguen constituyen las primeras manifestaciones, siempre según el CORDE, de esta construcción sin el auxilio de un verbo explícito. Si en el primer testimonio, ya comenzado el siglo xx, la interpretación es dudosa (la suspensión final no permite entender con claridad el sentido):

(29) El cuartel de Policía estaba lleno de campesinos reclamando sus caballos "requisados", y desaparecidos, o ya con dueño, de esos quia nominor leo. Bueyes, vacas, borregos ya digeridos, ni hablar.. Nada tiene tanto éxito como el éxito (1910, Gonzalo Zaldumbide, Égloga trágica, Ecuador),

a partir de 1950, su condición de secuencia que ha adquirido la capacidad de negar expresivamente es indudable; obsérvese que incluso cuando acompaña al infinitivo un incremento preposicional sobresale el valor de negación enfática, y que esta negación puede constituir por sí sola, pero no siempre es así, un enunciado independiente:

(30) "No hubo tales offsides", dice el señor Arqué. “¡...y ni hablar del gol fantasma de Calsita!” (1950, Coello, "Aquí el árbitro", en Marca, España).

(31) Del capote ignora hasta cómo se coge. Ya a finales de temporada aprendió la saltillera. Nada más. De banderillas, $n i$ hablar. Con la muleta ya quedó dicho cuál es su característica (1951, Francisco Montes, "La triste alternativa de Moro", en La lidia de México, México). 
(32) Tampoco tiene catedral, como Burgos, ni monumentos así para ir a ver. Las Arenas pase, por salir a la mar, pero el veraneo, ni hablar, y sin Isabel, el infierno (1956, Rafael Sánchez Mazas, La vida nueva de Pedrito de Andía, España).

(33) -¿Te vas conmigo?

-Déjamelo pensar...

-...deja que él se las avenga solo...

-No puedo.

-Que sí puedes.

-No puedo. Me da pena, ¿sabes? Por algo es mi padre.

-Entonces ni hablar. Iré a ver a la Juliana, que se desvive por mí (1955-1980, Juan Rulfo, Pedro Páramo, México).

Estas primeras apariciones no son, en absoluto, casos aislados; la secuencia ni hablar se manifiesta con este valor, desde 1950, abundante y creciente, hasta el extremo de haber convertido en excepcionales los usos que le preceden en el tiempo y cuya continuidad ya he señalado. Si antes me refería a la múltiple procedencia geográfica de los primeros testimonios en que ni hablar, dependiente de un verbo, manifestaba un valor expresivo, ahora debo destacar el mismo hecho: las manifestaciones de ni hablar como fórmula negativa expresiva se encuentran en textos producidos en varios países hispanohablantes, como se puede apreciar en los testimonios de este siglo. Es destacable, de nuevo (cf. supra), la localización de esta fórmula en pasajes, dialogados o no, que se circunscriben a una situación expresiva (es ya evidente, en muchos testimonios, la coloquialidad, real o reproducida por un autor literario). Obsérvese, por último, que desde estas primeras apariciones conviven los testimonios en que el infinitivo recibe un incremento preposicional (a menudo representado en eso y de eso, hasta el punto de que ni hablar de eso o [de] eso ni hablar pueden ser consideradas variantes de $n i$ hablar) con otros en que no hay desarrollo argumental:

(34) Bueno, puede que sea una buena chica, una infeliz. ¡Pero gente distinguida, como nos corresponde, ni hablar! (1951, Elena Soriano, Caza menor, España).

(35) En mis tiempos no ocurría esto... Eso sí, te decían algún piropo de pasada, pero en cuanto tú ponías la cara larga, ni hablar; te dejaban tan tranquila (1954, Ignacio Aldecoa, El fulgor y la sangre, España). 
(36) -Estos del minuto es tirar el dinero. Te sacan fatal. -Éstos ni hablar, por supuesto (1956, Rafael Sánchez Ferlosio, El Jarama, España).

(37) Y a mí, por las buenas lo que se quiera, ya se sabe, pero por las bravas ni hablar del peluquín ${ }^{21}$ (1958, Miguel Delibes, Diario de un emigrante, España).

(38) Lo único que tenía era orgullo, decía la Violeta, porque lo que es facha mejor ni hablar, y ni un peso (1966, José Donoso, Este domingo, Chile).

(39) Por eso el viaje fue todo un acontecimiento. Y un apurón, porque ninguna ropa decente ya le entraba. De zapatos, $n i$ hablar: hacía más de un año que no se calzaba (1970, Juan Bautista Rivarola, Yvypóra, Paraguay).

(40) Pero me tenéis que coger dos de cada brazo, para que os toquen a treinta kilos por barba, si no, ni hablar; no salgo (1968, Francisco García Pavón, El reinado de Witiza, España).

(41) Había fiesta en casa de una prima del Villa María y ahí ni hablar de llevar a la sueca, en Europa sí pero en Lima ni hablar (1970, Alfredo Bryce Echenique, Un mundo para Julius, Perú).

A partir de 1975, el CREA muestra un notable incremento de la presencia de ni hablar en todas las situaciones descritas hasta aquí, pero especialmente como fórmula de negación expresiva; con este valor se presenta en obras de ficción que reproducen situaciones de informalidad, pero también en prensa escrita y oral y en secuencias orales reales.

Los testimonios que ofrece la base de datos académica permiten observar que varían, como se aprecia en los casos aquí

21 La construcción ni hablar del peluquín, cuyo origen, según A. BuitrAGo (Diccionario de dichos y frases hechas, $15^{\mathrm{a}}$ ed., Espasa, Madrid, 2005, s.v.) pudo originarse en un chiste o chascarrillo en el que se obligara a alguien a ponerse o quitarse un peluquín, ofrece también sus primeras apariciones en esta época, en concreto, en el Diario de un emigrante de Miguel Delibes (siempre según CORDE), donde se encuentra en tres ocasiones. El hecho de que en el texto no reciba explicación prueba que debía de ser ya popularmente conocida. En A. Bryce Echenique, Un mundo para Julius-que ofrece abundantes testimonios de ni hablar-, se encuentra en dos ocasiones la variante ni hablar del peluquero, que no mencionan las obras lexicográficas consultadas. 
seleccionados, el grado de conservación del sentido literal del infinitivo (que guarda estrecha relación con la presencia de un complemento preposicional regido), y con él el recuerdo del predicado del que se hubiera descolgado la secuencia (no se puede, no quiero o similar). En cualquier caso, y como he propuesto al comenzar este trabajo, manifiestan que esta fórmula puede ser parte integrante de un enunciado (y por tanto locución):

(42) De performances, ni hablar... Se pone en marcha la generación nacida en el 85, y es el turno de los potrillos (1987, en El Clarin, Argentina).

(43) ¿Pero qué soy yo, un juguete? ¿Creéis que voy a serviros de pelele para resolver vuestras diferencias? Eso, ni hablar ; Me largo! (1990, María Luisa Luca de Tena, Un millón por una rosa, España).

(44) Se ve que, en aquellas sazones de los años 40, los "lletraferits" y los mallorquinistas -de catalanistas entonces $n i$ hablar- eran muy pocos (1994, Miguel Dolç, "Según mis ojos", en La Vanguardia, España).

(45) Y describe a Gustavo: "Como hijo, incomparable; como esposo y como persona, ni hablar" (1996, "Milagroso santo", en Proceso, México).

(46) Se trata de los útiles y materiales básicos para poder atender a una persona herida y ni hablar de intervenciones complicadas que van más allá de curita y alcohol (1997, "El conflicto cambió etiquetas”, en El Universal, Venezuela).

(47) Del enriquecimiento ilícito, ni hablar (1997, "La nota política", en El País, Colombia).

(48) Demasiados años sin toros. Como si se hubiera corrido la voz: encierros, ni hablar (1999, "Vuelve el encierro", en Diario de Navarra, España).

Y también constituir un enunciado fraseológico, en pasajes monológicos o dialogados:

(49) Porque viene el autobús, que oye, como para meterme yo allí con las lechugas. ¡Pues sí, hombre! ¡Se me espachurran los tomates! ¡Ni hablar! (1991, Canela en rama, punto de mira, Radio Vallecas B, España). 
(50) Te refieres por los toros y todo eso. Por los toros. Sí. No, ni hablar (1994, El peor programa de la semana, Televisión Española, España).

(51) Como comprenderán, resulta imposible contar toda la historia en un reportaje y mencionar a los nombres de los grandes maestros del blues a lo largo de un siglo, ¡ni hablar! (1996, “Tendencias”, en El Universal, Venezuela).

(52) - ¿Cuánto quieres por esto? -pregunta Cobra a uno de los hombres...

-No te vas a arrepentir, es de las buenas -le advierte el otro. -Por menos de diez soles, ni hablar (1998, Patricia de Souza, La mentira de un fauno, Perú).

(53) Pero en general en las ciudades grandes, ¡ni hablar!, en México o en San Pablo es fatal (sin fecha, entrevista [formalidad baja], Paraguay).

Por último, quisiera destacar que existe en la actualidad un valor escasamente documentado para ni hablar en sentido positivo, el de reafirmación (y en esto coincide con la fórmula en absoluto) que no encuentro registrado en los diccionarios y que se manifiesta, según he podido comprobar en el CREA, únicamente en Uruguay:

(54) De Moria aprendí muchísimo, con Bananita, con Miguel de Sel... y con Carballo ni hablar, bastaba mirarnos para saber que (sic) iba a decir el otro (2004, Guambia, Suplemento de humor del diario Últimas Noticias, segunda época).

(55) -Así que de los helados de Fuentes, tan famosos, ¿no te acordás?

-¡Pero sí, ni hablar! (2003, Guambia, Suplemento de humor del diario Últimas Noticias, segunda época).

LAS SEGUENGIAS NI PENSAR(LO), NI SOÑAR(LO).

DiAGronía y CONGURRENGIA PARADIGMÁTICA CON NI HABLAR

Como señalaba arriba, otras secuencias de estructura $n i+i n f i$ nitivo y que presentan también un verbo de lengua: ni decir ${ }^{22}$, ni

22 El verbo decir interviene, sin embargo, en numerosas expresiones. Véase C. Fernández Bernárdez, Expresiones metalingüisticas con el verbo 
desmentir, ni comentar, ni responder, ni contestar, etc., no han originado unidades fraseológicas. Todas ellas participan en contextos como los descritos para ni hablar: en una coordinación de infinitivos o como complementos únicos de un verbo:

(56) No deuen y cantar missa ni dezir amenos/de mandado del obispo (1256-1263, Alfonso X, Primera Partida).

(57) Ordenaron que ninguno non osas screuir ni dezir jamás (1379-1384, Juan Fernández de Heredia, traducción de Vidas paralelas, de Plutarco).

(58) ¿Quién sería... que podiesse contar ni screvir las armas y cavallos...? (1482-1492, Garci Rodríguez de Montalvo, Amadís de Gaula).

(59) Hay tantas cosas que no se pueden dezir ni contar (1534, Feliciano de Silva, Segunda Celestina).

(60) Y demás de ellas el que apenas se podrá referir, ni contar de otras Iglesias menores (1648, Juan de Solórzano y Pereira, Política indiana).

(61) Apenas podía estar de pie, ni responder a las preguntas de Hardyl (1786, Pedro Montengón, Eusebio).

(62) Y que sin Dios no puedo ni decir Jesús (1874-1878, sor Ángela de la Cruz, Papeles de conciencia. Diario espiritual).

(63) No crea, no crea, no se lo quiero ni decir (1973, Arturo Azuela, El tamaño del infierno).

(64) No se digna ni contestar (1951, Arturo Barea, La forja de un rebelde).

(65) Un crimen que no se puede ni contar (1956, Rafael Sánchez Ferlosio, El Jarama).

Pero los hablantes no les han concedido una transformación que las haya hecho capaces de modificar su sentido literal para manifestar rotundamente una negación o una negativa.

“decir", Universidade, Coruña, 2002, para las secuencias fijas o casi fijas (locuciones, colocaciones y enunciados fraseológicos) que incorporan este verbo en español. 
Sí, en cambio, han sufrido idéntico proceso al de ni hablar las secuencias ni pensar(lo), ni sonar(lo). Volviendo a la interpretación que he presentado acerca de la transformación de ni hablar en unidad fraseológica, quisiera ofrecer, porque entiendo que puede ser reveladora, una comparación con lo sucedido a estas fórmulas.

Una primera consideración lleva a señalar que no coincide su frecuencia de uso en nuestro idioma, sean cuales sean el valor que representen y la función que desempeñen, del mismo modo que difieren las frecuencias de los infinitivos que las integran, hablar, pensary soñar. De las tres secuencias, ni hablar es la más ampliamente representada, como cabía esperar teniendo en cuenta las actividades a las que aluden los infinitivos ${ }^{23}$, seguida, en este orden, de ni pensary de ni soñar.

$N i$ pensar (a menudo, también al igual que la secuencia $n i$ hablar, incrementada con un complemento, representado en la variante con clítico ni pensarlo ${ }^{24}$ ) ha recorrido un camino paralelo al descrito para ni hablar, aunque no exista coincidencia en la ubicación cronológica de sus etapas de transformación. Participa históricamente y sin interrupción en estructuras coordinadas (obsérvese que también ni pensar-a menudo junto al infinitivo hablar- se presenta en algunos casos como parte de un desarrollo expresivo, que desdobla la actividad en varias unidades léxicas, de aquello que se quiere negar, como en los testimonios 66 o 68 ):

(66) El amor no dexa saber ni pensar al enamorado (1495, Luis de Lucena, Repetición de amores).

(67) No digo hacer cosa contra su parecer, pero ni pensarla en mi pensamiento (1566, Juan de Timoneda, El Patrañuelo).

23 Hablar es, de los tres infinitivos aquí considerados, el de presencia más generosa en nuestro idioma en cualquier momento histórico, como se puede comprobar en el CORDE; le sigue de cerca pensar, y a larga distancia, soñar. En cuanto a las secuencias precedidas por ni, sirvan como representación de estas diferencias de frecuencia, sin tener en cuenta aquí el valor, los datos del siglo xx (hasta 1975): ni hablar, 131 testimonios; ni pensar, 89 testimonios; ni soñar, 18 testimonios.

24 Ésta es, por cierto, la única que mencionan los diccionarios académicos, según he podido comprobar en Real Academia Española, Nuevo tesoro lexicográfico de la lengua española, Espasa, Madrid, 2001, DVD-ROM -en adelante NTLLE. Y lo mismo sucede con ni soñarlo (id., véase infra), si bien el uso permite observar la presencia del infinitivo sin incremento pronominal o con un argumento distinto de un clítico: ni pensar en ello; eso, ni soñar. 
(68) Y reinará Dios en ellos solo y sin término que será estado mucho más feliz y glorioso de lo que ni hablar ni pensar se puede (1583, fray Luis de León, De los nombres de Cristo).

(69) Y si dice que no puede estar de rodillas ni pensar, estése allí sentado (1610-1612, san Juan Bautista de la Concepción, Exhortaciones a la perseverancia).

(70) Si debe ser inocente como la ley que representa, y no hacer ni pensar cosa indigna de su alto ministerio (1791-1809, Juan Meléndez Valdés, Discursos forenses).

(71) Pues hizo un movimiento que sin quererlo ni pensarlo yo, me obligó a cortarle el garguero (1867, José Mila y Vidaurre, El visitador).

(72) Parecen ajenos a la curiosidad de los mirones y dan la sensación de estar sorbiendo por los poros la paz del vacío, de no dar golpe ni pensar en nada (1971, Ángel Palomino, Gran Hotel Torremolinos).

Se encuentra con posterioridad, al igual que ni hablar, pero ya desde el siglo XVI (aunque muy escasamente hasta el xIX), y también sin interrupción hasta nuestros días, como único complemento de un verbo, contexto éste en el que el infinitivo viene a representar por sí solo la actividad mínima posible:

(73) Y, si supiesen cierto que en saliendo el alma del cuerpo ha de gozar de Dios, no les hace al caso ni pensar en la gloria que tienen los santos (1577, santa Teresa de Jesús, Las moradas del castillo interior).

(74) iJesús, qué chismería me hubieran armado en el curato! ¡Puf, ni pensarlo quiero! (1858, Juan Díaz Covarrubias, Gil Gómez, el insurgente: novela histórica).

(75) -Decirle que no, que no y que no -contestó Rosalía con enérgica resolución-. ¡Ah! ¡No quiero ni pensarlo! (1872, Benito Pérez Galdós, Rosalía).

(76) No quiero ni pensar la cara con que los recibiría (1960, Mario Benedetti, La tregua).

Por fin, esta secuencia manifiesta tempranamente -si bien el primer testimonio, del peruano Juan de Espinosa, es excep- 
cional y no vuelve a encontrarse otro hasta dos siglos más tarde- un caso en el que aparece sin el auxilio de un verbo y ya con valor de negación rotunda:

(77) Vigote: ...mas, juzgando / que sus parientes y deudos / venían a darme un chasco, / pedí favor.

Dina: Miedo fue.

Vigote: Absit, miedo, ni pensarlo (1688, Juan de Espinosa Medrano, Amar a su propia muerte).

A partir del siglo xix este valor se hace frecuente, en especial para la variante ni pensarlo, y, al igual que ni hablar, es locución y enunciado fraseológico. Obsérvese la plural procedencia geográfica también en el uso de esta fórmula:

(78) - ¿Yo casarme?, repetía Pomposa, eso sí que no; ni pensarlo (1818, José Joaquín Fernández de Lizardi, La Quijotita y su prima, México).

(79) Condesa (a Claudia): Un joven ni más ni menos / como usted, de pocos años, / y de mérito. Me ha dicho / que a usted toma sin reparo.

Ambrosio (con precipitación): ¡El señor Belton! Señora, / no es posible, ni pensarlo (1831, Jacinto de Salas y Quiroga, Claudia. Drama en tres actos, España).

(80) Para ti, cero, ni pensar en ello (1927-1930, Ramón del ValleInclán, La hija del capitán, en Martes de carnaval, España).

(81) En mi casa, desde luego, ni pensarlo... (1933-1946, Miguel Ángel Asturias, El señor presidente, Guatemala).

(82) - ¿Cuándo son las corridas de Valencia?

-Dentro de cinco días.

-No, señor, ¡ni pensarlo! (1947, José María Carretero, "El caballero audaz", en El libro de los toreros. De Joselito a Manolete, España).

(83) Maruja adivinó sus intenciones en el acto y quiso levantarse. -No... eso ni pensarlo, Manolo... (1966, Juan Marsé, Últimas tardes con Teresa, España).

(84) Los cuatrocientos soles de Itipaya se habían esfumado en el viaje y los tres primeros días en Lima no probó bocado. Había vagabundeado sin cesar... repasando nombres y eli- 
minándolos: Ludovico ni pensar, Hipólito seguiría en provincias o si había vuelto trabajaría con Ludovico, Hipólito ni pensar, él ni pensar. No había pensado en Amalia (1969, Mario Vargas Llosa, Conversación en la catedral, Perú).

La secuencia ni soñar(lo) completa, como he señalado, un paradigma de tres unidades fraseológicas de estructura y contenido coincidentes cuyo proceso de transformación ha recorrido las mismas etapas, aunque no se hayan verificado al mismo tiempo. Cabe señalar que ésta es, de las tres aquí consideradas, la de documentación más tardía, y también, como señalaba antes, la de menor presencia según la base de datos consultada.

Como formante de un período coordinado, se encuentra en el siglo XVI, pero el testimonio es único hasta el siglo XIX. Al igual que para las anteriormente examinadas, este uso continúa hasta hoy:

(85) De verdad yo no sabía decir ni soñar qué razón o qué repuesta tolerable podría dar la mujer cristiana (1528, Juan Justiniano, Instrucción de la mujer cristiana).

(86) Los grandes problemas religiosos que agitan y han de agitar aún el siglo presente, no sólo no podía resolverlo Martínez de la Rosa, pero ni soñarlos (1863, Juan Valera, "Sobre los discursos leídos en la Real Academia Española", en Estudios sobre historia y política).

(87) Pero sin exagerar el procedimiento, ni hacerle exclusivo, ni soñar en que Aristóteles no le había conocido y practicado (1880-1881, Marcelino Menéndez Pelayo, Historia de los heterodoxos españoles).

(88) Y eso no la dejaba ni dormir, ni soñar, ni ser feliz, ni nada (1980, Pedro Vergés, Sólo cenizas hallarás).

A pesar de sus escasas apariciones en el CORDE, casi al mismo tiempo es posible encontrar esta secuencia como complemento único de un verbo (también manifestada hasta la actualidad), siempre en contextos negativos, como representación de una actividad mínima posible. Es éste, por cierto, el valor más recurrente de ni soñar:

(89) Napoleón I no podía ni soñar que el previsor y cachazudo Moltke... calculaba al minuto la llegada (1872-1878, Carlos Coello, Cuentos inverosimiles). 
(90) ¿Pues acaso podías tú ni soñar con la fortunilla que te pienso ofrecer, farsantuelo? (1874, Benito Pérez Galdós, Napoleón en Chamartín).

(91) El que ha hecho accesible el especialista a los que antes no podían ni soñar en pagarlo (1946, Carlos García Oviedo, Tratado elemental de Derecho Social).

(92) Una abundancia de medios con lo que no podemos ni soñar por ahora (1950, Julio Casares, Introducción a la lexicografía moderna).

(93) Logró lo que sobre el campo no podía ni soñar, el 2-2 (2003, "Murcia 2-Atletic 2", en As).

$\mathrm{Y}$, finalmente, el siglo $\mathrm{xx}$ nos permite asistir a su transformación en unidad fraseológica -de presencia siempre discreta, aunque, como las anteriores, internacional- utilizada para la negación expresiva:

(94) -Mal se me dan las cosas.

-¡Mal, Joaquinito! Porque eso mío... ¡ni soñarlo! (1928, Jesús R. Coloma, "La lucha", en Lecturas, España).

(95) En cuanto a largarme a la otra Banda, en su busca, ni soñarlo, porque el gobierno no permitía los viajes (1962, Adolfo Bioy Casares, El gran Serafin, Argentina).

(96) En cuanto a recibir la visita de algún aspirante a marido, ni soñarlo (1977, Victoria Ocampo, Testimonios. Décima serie, Argentina).

(97) ¿Y si no tenemos las llaves? No, mira, si, si en el... si en la calle hay sitio... Eso, ni soñar (1991, oral, vehículo particular, conversación familiar, España).

(98) Pero ni soñar bachillerato, porque yo no estudié bachillerato porque la... mi papá murió (entrevista oral [formalidad baja], Venezuela).

(99) Me acuerdo mucho de los estampados grandes. Y ropa pegada, „ni soñar! Además, no nos llamaba la atención (sin fecha, entrevista oral [formalidad baja], Venezuela). 
NI HABLAR, NI PENSAR, NI SOÑAR EN LAS OBRAS LEXICOGRÁFICAS

He querido mostrar hasta aquí el proceso de conversión en unidades fraseológicas de tres secuencias estructuralmente idénticas cuya proximidad semántica -los significados de sus respectivos infinitivos, que se han tomado en algún momento como 'actividad mínima del ser humano', las ha dotado de la posibilidad de concurrir en los mismos contextos. Una vez alcanzada la condición de unidades fraseológicas cabía esperar, por parte de las obras lexicográficas, si no un trato idéntico para las tres expresiones, sí al menos una coincidencia cronológica con el uso que, según los datos que se han obtenido del CORDE y el CREA, manifiestan en nuestro idioma. No sucede siempre así. El examen de algunas obras lexicográficas muestra diferencias interesantes, como voy a tratar de mostrar ${ }^{25}$.

Era esperable, porque así sucede habitualmente, que los diccionarios no registraran las fórmulas hasta tiempo después de que éstas hubieran calado en el uso; y, en efecto, este desfase es el que se produce con ni hablary ni pensar.

En el caso de ni hablar, si el empleo como fórmula expresiva se registra a mediados del siglo xx, la Academia la incorpora en 1984 en el Diccionario manual, y reserva una entrada también para la variante ni hablar del peluquín:

Ni hablar: expresión que indica la no aceptación de una cosa. $\mathrm{Ni}$ hablar del peluquin: frase vulgar.

El Diccionario manual de 1989 incluye la misma información, pero, curiosamente, y tal vez sólo por olvido, las entradas desaparecen en el Diccionario usual de 1992. Interpreto la ausencia -al menos la de la secuencia ni hablar-como involuntaria, porque no sucede lo mismo con ni pensar (cf. infra sobre las secuencias ni pensar[lo], ni soñar[lo]), y porque la vigésima segunda edición la recupera (si bien desaparece la mención de la variante):

Ni hablar: expresión usada para rechazar o negar una propuesta.

El desfase cronológico es mayor para ni pensar(lo). Según se ha visto, esta secuencia se documenta con valor formulario desde el siglo XVII, y, sin embargo, la Academia la registra -siempre

25 La consulta de los diccionarios que aquí se citan está realizada por medio del NTLLE, salvo la 22a $\operatorname{del} D R A E$, que he manejado directamente. 
exclusivamente con incremento pronominal-al mismo tiempo que ni hablar, en $1985^{26}$, en el Diccionario manual:

Ni pensarlo: frase familiar. Se usa generalmente en tono exclamativo para rehusar o rechazar algo.

La edición de 1989 del Diccionario manual reproduce la misma entrada. En el Diccionario usual de 1992 se cambia la consideración de frase por la de expresión, y se añade la valoración "figurada" que alude a su idiomaticidad:

Ni pensarlo: expresión figurada con que se niega el permiso para hacer algo.

Esta valoración desaparece en la edición de 2001:

Ni pensarlo: expresión usada para negar el permiso para hacer algo.

Así pues, ambas fórmulas coinciden, según puede apreciarse, en su fecha de incorporación a los diccionarios académicos, que optan, también a un tiempo, por la denominación "frase" o "expresión".

Si el desfase de las obras lexicográficas respecto del uso es habitual, lo contrario, es decir, que los diccionarios se anticipen a los testimonios, resulta sorprendente y obliga a buscar una razón. Pues bien, esto es lo que sucede con la fórmula $n i$ soñar(lo); la base de datos consultada no ofrece testimonios de su empleo como unidad fraseológica hasta el siglo xx, y aun a partir de esta fecha es la de menor presencia de las aquí consideradas $^{27}$. Frente a esta ausencia de testimonios, la Academia le concede un espacio en sus obras lexicográficas desde 1739, esto es, desde el Diccionario de Autoridades (tomo S-Z) ${ }^{28}$, que le dedica

26 Tampoco la incluyen otros diccionarios anteriores consultados por medio del NTLLE.

27 Entre 1901 y 1975 ni soñarlo se encuentra en tres ocasiones, y ni soñar, que aparece, no ofrece ningún testimonio de su valor formulario (esto es, sólo se presenta como formante de una secuencia sintáctica superior). Desde 1975, ni soñarlo ofrece nueve testimonios como unidad fraseológica, y $n i$ soñar, ocho.

28 Véase NTLLE. No la encuentro en dicccionarios anteriores; por tanto, ésta puede ser la primera mención. 
este comentario (si bien no la autoriza) generoso y esclarecedor acerca de la motivación que originó esta fórmula:

Ni soñarlo: phrase con que explicamos estar tan lejos de alguna especie que ni aun por sueño se haya ofrecido al pensamiento.

Es más que factible, por tanto, que el CORDE oculte el uso real de esta fórmula, probablemente circunscrita a un ámbito (el de la informalidad) que no se deja ver en los textos reproducidos. De hecho, le conceden también una entrada en sus diccionarios Núñez de Taboada (1825), Salvá (1846), Domínguez (1853), Gaspar y Roig (1855), Zerolo (1895), Alemany y Bolufer (1917) y Pagés $(1931)^{29}$.

Tras la primera mención académica, la incorporan todas las ediciones del Diccionario usual hasta nuestros días, y también las del Diccionario manual ${ }^{30}$. La edición de 1884 del Diccionario usual añade, a la consideración de frase, una valoración: "figurada y familiar", que permanece hasta hoy. En el Diccionario manual de 1985 se cambia (compárese este dato con lo dicho para las fórmulas arriba mencionadas) "frase" por "expresión", se añade información sobre la variedad diafásica en la que se produce y se mantienen las precisiones sobre su idiomaticidad y la interpretación que le dio origen:

Ni soñarlo: expresión figurada y familiar con que explicamos estar lejos de una cosa, y que ni por sueño se nos ha ofrecido al pensamiento tal cosa, o con que indicamos la seguridad que uno tiene de que no existe o no va a ocurrir cierta cosa.

El Diccionario usual de 1992 vuelve a la versión de ediciones anteriores, y anota por vez primera, en entrada aparte, su capacidad de actuar como fórmula de recusación:

Ni soñarlo: frase figurada y familiar con que explicamos estar lejos de un asunto, y que ni aun por sueño se haya ofrecido al pensamiento. //Se usa en tono exclamativo para rehusar o rechazar algo.

29 Véase NTLLE, s.v. "soñar".

30 El Diccionario manual, publicado en 1927, y que conoce sucesivas ediciones en 1950, 1985 y 1989, recoge siempre una versión más breve de esta definición (salvo en la de 1985): 'frase con que explicamos estar lejos de una especie' (véase NTLLE). 
Esta separación se mantiene en 2001, pero se actualizan los términos:

Ni soñarlo. 1. Expresión coloquial. Se usa para explicar que se está lejos de un asunto, y que ni aun por sueño se ha ofrecido al pensamiento. 2. Locución interjectiva. Se usa para rehusar o rechazar algo.

Dejando a un lado las diferencias cronológicas y los apelativos de "frase" o "expresión", que tampoco coinciden siempre para unas y otras, tal vez lo más llamativo es comprobar que las tres fórmulas aquí consideradas reciben descripciones diferentes, y que, según las interpretaciones que se ofrecen, no se trata de unidades fraseológicas sinónimas. Obsérvese, en las definiciones arriba reproducidas del Diccionario académico de 2001, que sólo ni soñarlo es locución ${ }^{31}$, y también que sólo ésta aparece circunscrita al ámbito coloquial. Además, si bien el uso las hace aparecer como intercambiables, en el Diccionario se asocian, respectivamente, al rechazo de una propuesta -ni hablar, ni soñarloa la negación de un permiso - ni pensarlo- y a la negación expresiva -únicamente ni soñarlo.

Como prueba, sin embargo, de la intercambiabilidad pueden servir los testimonios que aquí reproduzco organizados según las descripciones que ofrece la Real Academia (algunos ya citados a lo largo de este trabajo). En todos ellos sería posible sustituir una fórmula por otra (con el oportuno cambio de régimen si este aparece) sin que se produzca alteración del valor pragmático (si es que una respuesta negativa o un permiso denegado no pueden considerarse también, formulados con estas secuencias, negaciones expresivas):

Negación expresiva

(100) En cuanto a recibir la visita de algún aspirante a marido, ni soñarlo (1977, Victoria Ocampo, Testimonios. Décima serie).

31 En cambio, M. SEco, O. AndRÉs y G. RAmos consideran exclusivamente locución adverbial ni pensarlo (o ni lo pienses), y sólo anotan como coloquial ni soñarlo (o ni lo sueñes). En cuanto a la descripción de su valor, encuentran ni soñarlo y ni pensarlo aptas para la negación enfática, y ni hablar para el rechazo, es decir, de acuerdo con el valor dialógico que subyace siempre para hablar antes comentado (Diccionario fraseológico documentado...). M. Moliner (op. cit., s.v. "hablar", "pensar" y "soñar"), anota ni hablar como expresión, y ni pensarlo, ni soñarlo como frases. Sin embargo, en este diccionario coinciden en recibir la caracterización como expresivas de negación o de rechazo, y también en su valor generalmente exclamativo. 
(101) Si el Roda estuviese en Primera División, seguro que se desplazaban hasta aquí sin problemas. Pero venirse de romería en enero, ni pensarlo (1983, José Antonio Labordeta, Aragón en la mochila).

(102) -Ha vendido usted una parte de la banca Matutes... -Yo, ni hablar (1990, "Nunca ha recibido ni dado comisiones", en El Tiempo).

(103) Y si eso sucede con los niños que pasan en el colegio, ni hablar con los que no lo logran (1997, "Las pruebas de admisión: ¿otra forma de maltrato infantil?”, en El Tiempo).

Negación de permiso

(104) ¿Y si hubieras nacido en otro tiempo? ¿O si de perdida estuvieras inscrito en otra escuela? Ah, ni pensarlo: "te puedes cambiar de escuela siempre y cuando encuentres una mejor" (1980, Gerardo María, Fábrica de conciencias descompuestas).

(105) Los permisos los dan con cuentagotas, y siempre a los mismos. A nosotros nos tienen por reboleras y de permiso ni soñarlo (1984, José Luis Tomás García, La otra orilla de la droga).

Rechazo de propuesta

(106) Pero cuando vi que decía: título provisional Memorias, dije que ni hablar, que yo no firmaba aquel contrato (1981, "Próxima aparición en España de la autobiografía de la actriz...", en El País).

(107) Y... y luego pues, pues eso, que te dije: "Yo, ni hablar, ¿Filosofía y Letras?, ¡qué va, ni hablar!” (oral, mujer de 20 años, abogada).

(108) Aquí los tiene. Puede llevárselos; pero no olvide devolvérmelos... ¿Publicarlo? Hombre, eso ni soñarlo (1989, Miguel Sánchez-Ortiz, La gran ilusión).

(109) -...Pensaron que íbamos a pasar una velada formal con cubiertos de plata y hablando de antepasados.

-Sí, de abuelos emigrados a Cuba -rió Emilia.

-Pues ni pensarlo (2002, Alicia Giménez Bartlett, Serpientes en el paraíso. El nuevo caso de Petra Delicado).

No obstante, puede ser interesante comprobar, mediante un análisis exhaustivo de su uso actual, si efectivamente estas fórmulas se especializan para uno u otro valor. 
FINAL

El español de hoy dispone de un paradigma de tres secuencias sinónimas en su valor pragmático y de igual estructura: ni hablar (de eso), ni pensar(lo), ni soñar(lo) (integradas, claro está, en otro superior, el de las fórmulas especializadas en la recusación), cuyo proceso de transformación, de secuencias libres con significado pleno a unidades fraseológicas de valor idiomático, originado por una interpretación común, he querido presentar y analizar en estas páginas.

La necesaria cautela, y especialmente la comprobación del desfase que existe entre el uso documentado y la fecha en la que los diccionarios incorporan ni soñar(lo), obligan a dejar constancia de que es muy probable que las bases de datos consultadas no reflejen el uso real de estas fórmulas, que, surgidas en el registro informal, podrían hallarse en textos no incorporados en el CORDE. Así pues, la búsqueda de la presencia histórica de estas y otras secuencias similares habrá de continuar, fuera de esta fuente, en otros tipos de texto. Ahora bien, aunque los datos hallados no resulten por completo fiables desde el punto de vista cronológico, la coincidencia de los tres procesos de conversión lleva a pensar que la transformación sintáctica y semántica de estas tres secuencias pudo haber sucedido como aquí he querido mostrar.

Carmela Pérez-Salazar Resano Universidad de Navarra 